rubou o governo peronista tentou resolver este problema. E assim que se abre a segunda etapa de acumulação de capital que passou a depender da exploração intensiva de mão-de-obra. A importação de bens de capital e tecnologia tornou-se exigência para se restituir o nivel satisfatório dos lucros industriais. Politicamente esta nova situação supõe a exclusão do operariado e a formação de uma aliança entre burguesia associada ao capital estrangeiro e à oligarquia latifundiária. Além disso, exige uma nova atitude da pequena e média burguesia nacional que rompe a aliança anterior com o operariado e cada vez mais busca vinculações com o capital estrangeiro.

Nesta segunda fase, a burguesia ligada aos capitais altamente tecnológicos, apossa-se progressivamente do poder político e consegue garantir sua hegemonia, em detrimento dos setores tradicionais, principalmente após o golpe militar do Gen. Aramburu, impondo sérias restrições ao movimento peronista.

Neste momento, a elevada produtividade industrial, o baixo incremento de mão-de-obra neste setor, resultou num elevado nivel de desemprego, principalmente nas regiốes do interior. Além disso, o processo de concentração industrial que atinge um grau considerável (pelo censo de 1963, $69 \%$ da indústria argentina é altamente concentrada) vai diversificar a situação da classe operária, relativamente homogênea no período anterior. As indústrias com maior participação de capital estrangeiro e, por isso mesmo,

com elevada concentração de capital têm possibilidades de elevar os salários dos operários, criando uma elite em relação à classe como um todo.

De 1955 a 1966, ocorre um fracionamento do movimento peronista sindical e político. Surgem, no âmbito sindical, tendências conciliatórias, conhecidas freqüentemente como "integracionismo", "colaboracionismo" ou "participacionismo". E justamente esta aristocracia operária a defensora de uma política colaboracionista entre as classes, contri- buindo, decisivamente, para o fracionamento do movimento peronista.

A partir de 1966, a fração colaboracionista é questionada pelo peronismo ortodoxo que passa por um processo de radicalização, adotando novas estratégias de cunho revulucionário. Neste momento. a política reformista está perdendo o apoio das bases sindicais frente a sua ineficiência em defesa dos interesses da classe.

Por outrc iado, a marginalidade a que foi relegada a maioria da classe operária, em virtude do processo de acumulação de capital, forneceu as condiçôes estruturais para a consolidaçăo de uma estratégia revolucionária. $\mathrm{O}$ peronismo revolucionário, surgido em 1968, firma, no Congresso de Córdoba, em 1969, uma política radical de tomada do poder, fato que caracteriza a fase atual do peronismo.

Assim, este livro de Mônica Peralta Ramos, parte de sua tese de doutoramento, é uma obra rica em profundidade, principalmente porque revela as condições estruturais que explicam a emergência do processo político argentino. Além disso, apresenta uma quantidade considerável de dados sobre a indústria argentina que podem ser proveitosamente utilizados por outros estudiosos.

Volia Regina Costa Kato

\section{Bairros Rurais Paulistas}

Por Maria Isaura Pereira de Queiroz. Livraria Duas Cidades, 1973. $157 \mathrm{p}$.

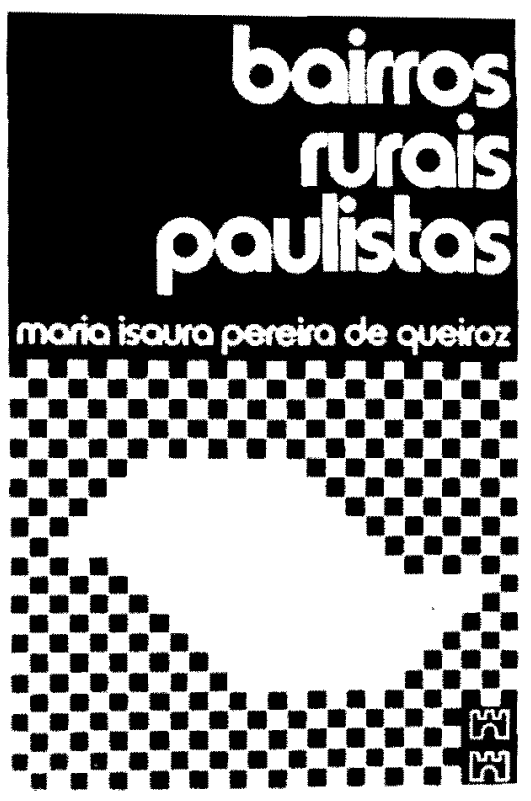

Como parte dos estudos sobre a organização e funcionamento da sociedade rural paulista, Maria Isaura procura nesta obra desenvolver a concepção de bairro rural, através de pesquisas feitas em Taubaté, Leme, Paraibuna e Itapecirica.

As definições anteriores de bairro rural consideram-no como "unidade mínima de povoamento das áreas rurais paulistas"; seria "um grupo de habitat disperso", composto por pequenos proprietários ou parceiros, e que se constitui em torno de um núcleo, geralmente uma capela. Sobressaem nas suas caracteristicas os elementos sociais e culturais, como a solidariedade, a ajuda mútua, expressas sobretudo no mutirăo; o folclore, demonstrado principalmente nas festas religiosas, momentos de reuniăo de todas as famílias no núcleo central.

Ainda mais, os bairros rurais vêm sendo apontados como próprios da civilização caipira, que se desenvolveu nas áreas de povoamento mais antigo. Com uma economia tipicamente de subsistência, com necessidades mínimas de consumo, marginalizados da economia regional, estariam 
fadados a se desestruturarem e desaparecerem com o surgimento de empreendimentos agricolas modernos. A proximidade de centros urbanos importantes seria outro fator para a desagregação das formas sociais e culturais próprias dos bairros.

E principalmente o plano da caracterização econômica que as pesquisas de Maria Isaura colocam em cheque. Num rápido apanhado, surgem realidades' que não se coadunam com a inclusão necessária de elementos como economia de subsistência, marginalização econômica, povoamento antigo, necessidades mínimas de consumo, na conceituação de bairros rurais.

Por sua vez, a análise das relaçōes dos bairros com a sociedade global, que constitui uma das preocupações básicas da autora, permite nova visão sobre as influências recíprocas entre meio rural e urbano, que contestam a hipótese de desagregação frente a proximidade de centros mais desenvolvidos.

As pesquisas foram feitas em bairros rurais de quatro municípios. Cada um deles apresenta uma problemática particular:

1. Os dois bairros rurais estudados no municipio de Taubaté enquadram-se na conceituaçăo clássica: extremamente pobres, com economia de subsistência, atc. Mas levanta-se uma contradição: o núcleo urbano do município passa por um rápido desenvolvimento industrial, tornando-se autônomo do meio rural. Entretanto os bairros, dele distantes apenas $16 \mathrm{~km}$, em nada são alterados na sua estrutura tradicional por esta proximidade.

2. Taquari, bairro rural do municlpio de Leme, constitui, a nosso ver, 0 exemplo mais interessante. Embora composto por pequenos proprietários e parceiros, as suas produções principais (algodão e mandioca) destinam-se à comercialização. 0 bairro encontra-se em situação relativamente próspera, com hábitos de consumo modernizados; situa-se em região de colonização mais recente, tendo absorvido muitos imigrantes estrangeiros.
Mantém, todavia, as formas de ajuda mútua, reunião, festas sociais e religiosas, que caracterizam um bairro rural, em pleno funcionamento. Aliás, a modernização econômica leva a maior vitalidade dos componentes sociais e culturais: festas muito mais freqüentes, mais ricas, etc. Outro fator interessante é que os imigrantes, ao invés de inovarem a cultura caipira, foram nela integrados.

Ainda aqui temos uma situaçăo em que a relativa prosperidade do bairro rural contrasta com o pouco desenvolvimento do núcleo urbano, que continua apêndice do meio rural. Economicamente, a zona rural liga-se diretamente com outros municipios mais importantes da região, tanto para a comercialização dos produtos quanto para a aquisição de maquinaria, insumos, etc., dispensando o núcleo urbano do municipio de Leme.

3. Para a autora, o exemplo de Paraibuna é um dos elementos importantes para a sua reconceituação de bairro rural: nos bairros pesquisados neste município encontra-se uma produção de leite que é voltada principalmente para a comercialização e "que é coletada diariamente pelos caminhōes da Usina Vigor ou da Cooperativa de Laticinios, ambas sediadas em São José dos Campos". Temos aqui também um caso de integração econômica na região, passando por cima do núcleo urbano do municipio.

4. É apenas em Itapecirica que encontramos desestruturação e decadência dos baírros rurais. Aqui a autora nos dá uma síntese do processo econômico da área, concentrando a análise em dois bairros rurais: Palmeiras e Laranjeiras. Até a década de 1930 , aproximadamente, a economia organizada à base da pequena propriedade, centrava-se numa policultura, cujos excedentes eram escoados para São Paulo. Entretanto o desenvolvimento da capital paulista, 0 aumento das suas necessidades, fez com que surgissem novas áreas abastecedoras de produtos agrícolas, o que levou a região a perder a sua antiga posição de supridora do mercado paulistano. Por esta época, a agricultura foi em grande parte substituida pela extração do carvão, o que levou a uma efêmera prosperidade. A extração do carvão desorganizou a economia até então típica da área.

Por sua vez, com o declínio da extração de carvão, os dois bairros reagiram diferentemente: Laranjeiras entrou em completa decadência e miséria; Palmeiras, ao contrário, com a abertura da $B R-2$, integrou-se num novo tipo de estrutura de trabalho: os elementos do bairro empregam-se como choferes de caminhão, abrem vendas à beira da estrada; enfim, surgem novas perspectivas econômicas. Entretanto, da mesma forma que em Laranjeiras, o bairro rural entra em vias de extinção, pois as novas relações de trabalho não permitem a manutenção das formas associativas próprias.

Finalmente, conclui-se das pesquisas realizadas que o fundamental para a constituição e permanência de um bairro rural é a existência de determinadas formas de propriedade e de relações de trabalho - a pequena propriedade com base no trabaIho familiar, contando ocasionalmente com a ajuda de alguns assalariados. Esta organização do trabalho é especifica da camada social formada por sitiantes e roceiros, e leva à existência de formas sociais e culturais próprias. Este tipo de economia e de organização social pode desenvolver-se a qualquer momento, não sendo especifico das áreas tradicionais.

Desta forma, elementos como economia de subsistência ou comercializada, majores ou menores necessidades de consumo, etc., podem constituir-se em fatores para distinguir diferentes tipos de bairros rurais.

Acreditamos que, além desta nova conceituação dos bairros rurais, uma das contribuições mais importantes da obra é mostrar que eles podem ser integrados economicamente, desempenhando papel funcional na estrutura econômica mais geral, o que eli- 
mina a inevitabilidade de sua decadência, que constitui apenas tendência para certos casos.

Procuramos destacar aspectos que mais nos chamaram a atenção na obra, o que de modo algum esgota as várias contribuições que traz.

A comparação das concepções de vários autores sobre bairros rurais, o questionamento de certo tipo de divisão econômico-social do Estado de São Paulo, a exposição dos métodos utilizados nas pesquisas, a caracterização dos municípios em que se localizam os bairros estudados, bem como a descrição detalhada destes últimos, do seu funcionamento, das relações com os núcleos urbanos e regiões, são outras tantas contribuições a assinalar.

No entanto a obra parece-nos ser um tanto repetitiva nas análises e conclusões. No estudo de cada unidade pesquisada, repisam-se, de modo desnecessário, os pressupostos utilizados e as hipóteses que se vão formulando. As teses da autora, entretanto, contribuem para novas discussões sobre o bairro rural. Desta forma, a obra constitui mais uma contribuição à literatura existente e sua leitura é necessária para o estudo do problema do bairro rural.

Marisa Saenz Leme

\section{Brancos e Pretos na Bahia}

Por Donald Pierson. 2 ed. São Paulo, Companhia Editora $\mathrm{Na}$ cional, 1971. 430 p. (Coleção Brasiliana, v. 241).
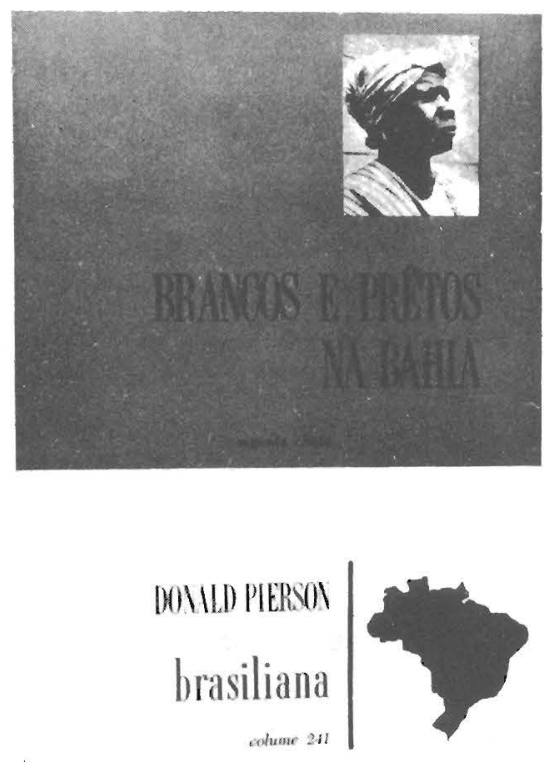

Enquanto na década de 30 proliferavam no Brasil estudos culturalistas sobre os negros, enfatizando aspectos religiosos, folclóricos, lingüísticos, etc., o tema "negro" mantinha-se excluído das preocupações sociológicas da época, então essencialmente ensaísticas.

Esta obra de Donald Pierson, baseada em pesquisas realizadas entre 1935 e 1937 na Bahia, surgiu como trabalho isolado, posto que orientada de modo totalmente original. $O$ autor vinha ao Brasil fundamentado na sociologia americana incrementada por Robert Park, Robert Redfield, Louis Wirth, Herbert Blumer e outros. Desenvolveu observação cuidadosa, procurou conseguir intimidade com o objeto de análise residindo em diferentes pontos da cidade de Salvador, participando tanto quanto possível das atividades culturais da população de cor; estudou documentos e levantou dados sobre a distribuição da pupulação na cidade, as atividades econômicas mais características, etc.; valeu-se de questionários aplicados a estu- dantes e de entrevistas diversas, depoimentos escritos, enfim, conseguiu reunir uma massa de dados empíricos totalmente inédita, a que conferiu tratamento estatístico. Talvez este seja seu maior mérito. Além disso, considerou em larga escala os estudos feitos anteriormente sobre o assunto, quer por brasileiros, quer por estrangeiros, comparando os resultados que ia obtendo com os deles. Assumiu atitude durkheimiana diante do objeto de estudo, ao pretender isentar-se de envolvimentos emocionais ou valorativos, dispondo-se a descrever e analisar, tão-somente.

Pierson veio ao Brasil com o intuito de proceder a um estudo sistematizado e objetivo das relações de raça, pois aqui se apresentava um dos mais importantes melting-pots de raças e culturas, numa época em que, tanto a Europa quanto os Estado Unidos e outros, se viam às voltas com questões raciais. Foi justamente a ausência de "problema racial" no Brasil que chamou sua atenção. Percebe-se, por isso, que desde o início do trabalho houve um quadro de referências implícito, qual seja, o das relações raciais na sociedade com a qual o autor estava familiarizado: a norte-americana.

No decorrer de toda a obra há referências comparativas, que enfatizam ou reafirmam o caráter típico das relações raciais nas duas sociedades: a inexistência de uma "linha de cor" rígida, a organização social baseada em classes abertas, a política assimilacionista por parte dos "brancos" e a ideologia (não formal) da democracia racial, na sociedade brasileira; a demarcação rígida entre negros e brancos, a existência de verdadeiras castas separando esses grupos e a consciência dos negros como "minoria", nos Estados Unidos.

Pierson aponta as dificuldades que encontrou diante da necessidade de conceituar "cor" e "raça" na Bahia, pois não encontrou "grupos" característicos, de acordo com o sentido científico do termo e sim agregados estatísticos somente, visíveis apenas para o observador. Considerando 